\title{
The Effects of Transcutaneous Electrical Stimulation on the Healing of Radial Fracture in Rabbit
}

\author{
${ }^{1}$ D. Sharifi, ${ }^{2}$ P. Yunessi, ${ }^{3}$ F. Sasani and ${ }^{4}$ S. Mohitmafi \\ ${ }^{1}$ Department of Clinical Sciences, Faculty of Veterinary Medicine, University of Tehran, Tehran, Iran \\ ${ }^{2}$ Graduate from IslamicAzad Veterinary College, Karaj Unit, Tehran, Iran \\ Department of Pathology, Faculty of Veterinary Medicine, University of Tehran, Tehran, Iran \\ ${ }^{4}$ Faculty Member of Islamic Azad Veterinary College, Karaj Unit, Tehran, Iran
}

\begin{abstract}
The study was performed on 10 New Zealand white rabbits 6 months old and weighing 3.0 to 4 . $5 \mathrm{~kg}$ so as to evaluate the effects of Transcutaneous Electrical Stimulation (TES) on the right radial fracture healing. A piece of $0.5 \mathrm{~cm}$ full thickness of right midshaft of radial bone was removed in all rabbits under general anesthesia. They were divided into two groups (control and experimental) of 5 rabbits each. No treatment was given to control group, whereas experimental rabbits were subjected to TES. Radiographs were taken from all rabbits before surgery and on 15,30 and 45 days. The callus sample was collected from the exact defected part on 45 days that was fixed and was stained with H\&E method for histomorphological interpretation. Clinically there was faster skin wound healing in experimental rabbits as compared to the control group. Radiographical interpretation revealed periosteal reaction on 15 days and callus formation was much more on 30 and 45 days/ in experimental one as compared to control group. In experimental group there was the least cartilaginous and fibrotic tissues with thick bony trabeculae formation. It was concluded that TES has got positive effect on skin wound healing besides accelerating callus formation at the site of radial defect with early restoration of full limb function.
\end{abstract}

Key words: Transcutaneous electrical stimulation, radial fracture, rabbit, skin wound healing

\section{INTRODUCTION}

Different method of internal and external fixation and even bone graft $^{\mathrm{m}}$ beside physical modalities has been advocated for fracture repair. Each techniques has it's own advantages and disadvantages, noninvasive physical therapy with having the least side-effect can be applied in animals as to accelerate cellulardifferentiation and increase the potency of osteogenesis and shortening the healing period ${ }^{[1-4]}$. Therapeutic ultrasound,electromagnetic, acupuncture, electrical stimulation and even laser have been reported ${ }^{[5-}$ 10]. Transcutaneous electrical stimulation because of its ability to stimulate ${ }^{[5]}$ physiology and growth factors at tissue level, its effect and importance will be evaluated on bone healing in this study.

\section{MATERIALS AND METHODS}

This experiment was done using 10 clinically healthy New Zealand white rabbits 6 months old and weighing 3.0 to $4.5 \mathrm{~kg}$ that maintained under similar housing and feeding conditions after approval was received by the University Research Committee. The experiment was done in accordance with usual guidelines. A piece of $0.5 \mathrm{~cm}$ in length of full thickness of right midshaft of radial bone was removed by using electric bone cutter, in all rabbits under general anesthesia induced by combination of ketamine hydrochloride $35 \mathrm{mg} / \mathrm{kg} / \mathrm{BW}$, Xylazin $5 \mathrm{mg} / \mathrm{kg} / \mathrm{BW}$, diazepam $1 \mathrm{mg} / \mathrm{kg} / \mathrm{BW}$ and acepromazine maleate $1 \mathrm{mg} / \mathrm{kg} / \mathrm{BW}$. After full recovery from anesthesia they were divided into two groups (control and experimental) of 5 rabbits each. No treatment was given to control group whereas experimental rabbits were subjected to transcutaneous electrical stimulation therapeutic regimen after $3^{\text {rd }}$ day of surgery for 10 min during 15 days with $70 \mathrm{~Hz}$ frequency. The fractured bone was externally fixed with bilateral coaptation-splint for first two weeks. Each of them was kept in special box as to restrain during therapy. The full surface $\left(1 \mathrm{~cm}^{2}\right)$ of electrode covered with pad soaked in water properly was placed close contact to proximal part of fractured site (2 positive electrodes) and distal part (2 negative electrodes) which were subsequently fixed with adhesive tape. Daily clinical signs were recorded and radiographs were obtained before operation and on 15, 30 and 45 post- operative days on lateromedial position. Callus sample was collected from defected area of radial bone of each rabbit on 45 post operative days. Animals were euthanized by overdose of thiopental sodium. The

\footnotetext{
Corresponding Author:

Dr. Davood Sharifi, Assoc. Prof. Surgery \& Radiology, Department of Clinical Sciences, Faculty of Veterinary Medicine, University of Tehran, Tehran, Iran, P. O. Box 14155-6453, Fax: 00982166933222, Tel: 0098-21-66920035
} 
sample was fixed in $10 \%$ formalin then decalcified in $5 \%$ nitric acid $^{[7]}$. After sectioning they were stained with H\&E method for histomorphological interpretation.

\section{RESULTS AND DISCUSSION}

The anesthetic protocol was quite effective in inducing deep and satisfactory anesthesia in $6.2 \pm 0.8 \mathrm{~min}$ for the first $20 \mathrm{~min}$ without any clinical side effect. The full recovery was on $82.4 \pm 3.2 \mathrm{~min}$. Clinically there was much better union of skin edges at the site of incision in experimental group on second week as compared to control group. The radiographic evaluation of the fracture part at 15 days indicated the bone healing was discernible in experimental rabbits but haziness and blurring of fracture gap was observed in control rabbits. Fracture line was clearly visible in this control group (Fig. 1). The periosteal reaction with evidence of callus formation (lipping) from proximal and distal fragment was seen in experimental rabbits (Fig. 2). On day 30 in all rabbits of experimental group, bridging of the gap with well marked periosteal callus from both ends of broken bone fragment was noticed in periosteal collar form with evidence of moderate calcification (Fig. 2). Cleavage of fracture line was still distinct despite of endosteal reaction in control group (Fig. 1). On 45 days the fracture gap was filled up with variable dense callus. The fracture gap was organized in experimental rabbits than to control group. Radiographs indicated that resolution and remodeling of callus has almost occurred. It had been streamlined to resemble with a more compact bone with regular border in experimental rabbits (Fig. 2) the adhesion were more extensive in control group than to the experimental rabbits. The callus appeared irregular and sufficiently elevated from the adjacent periosteal tissues. Only few foci of adhesions were presented between the site of fracture and the surrounding tissue. The callus surface was smoother and distinctly raised from periosteal surface. Hematoxylin and eosin staining of normal bony biopsy indicated regular, impact bony thick trabeculae with osteocytes in lacunae. Callus samples from control group revealed that the hematoma had almost completely been replaced with mixtures of dense fibrous tissue. There were inflammatory cells and different grade of cartilaginous tissue having angioblastic activity with variable thin boney trabeculae in this group (Fig. 3 and 4). The ossification was more advanced with osteogenic activity in newly ossified callus in experimental group. Formation of haversian system in the newly formed bone was quite comparable with normal group. Remodeling was noticeable in its initial phase around the bone bordering the fracture gap in experimental group (Fig. 5 and 6).

Radial and ulnar and tibial fractures are common in rabbits. Partial and total loss of function of limb caused by fracture has direct effect on the locomotion of animals

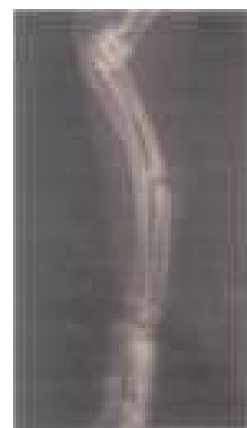

Radiograph taken on 15 days on lateromedial position in control group

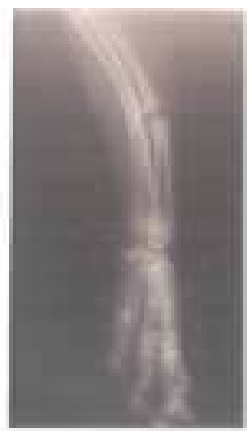

Radiograph taken on 30 days on lateromedial position in control group

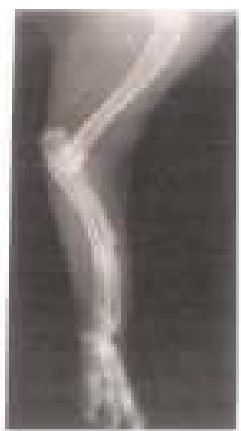

Radiograph taken on 45 days on lateromedial position in control group
Fig .1: Radiograph taken on 15,30 and 45 days in control group

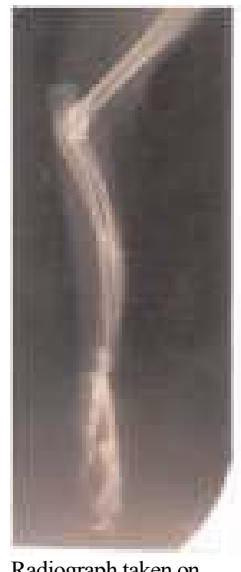

Radiograph taken on 15 days on lateromedial position in

Experimental group

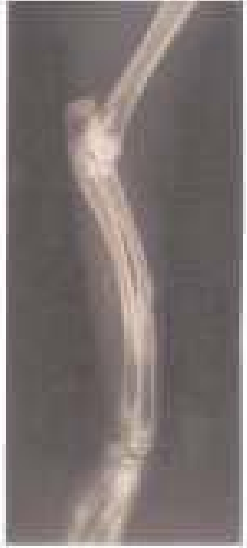

Radiograph taken on 30 days on lateromedial position in Experimental group

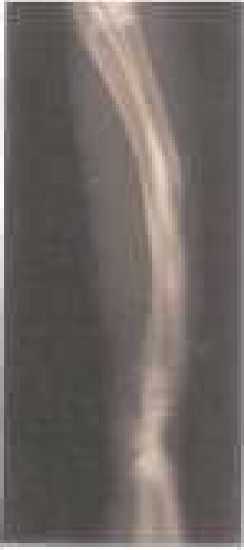

Radiograph taken on 45 days on lateromedial position in Experimental group
Fig. 2: Radiograph taken on 15,30 and 45 days in experimental group

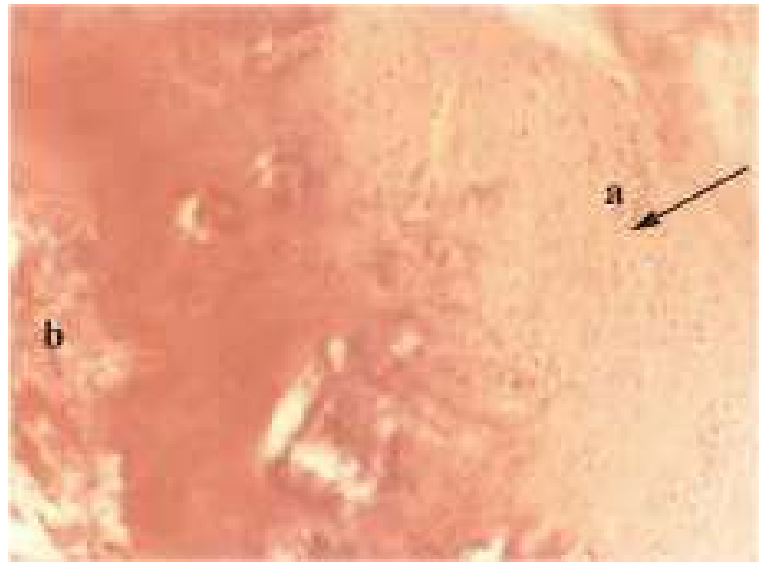

Fig. 3: Newly formed fibrocartilage in control group (X100 H\&E). a: chondroblast b: fibrous tissue

with some significant advancement made in the recent year, immobilization and healing of radial or tibial fracture can be well assured even in laboratory animal ${ }^{[9]}$ but healing alone is not enough. Restoration of function of the part 
healed is the ultimate objective. Effective surgical anesthesia in rabbits is difficult to achieve due to susceptibility of this species to apnea associated with use of volatile anesthetics and difficulty of endotracheal intubation $^{[11]}$. The inj ectable anesthetics like Ketamine hydrochloride either alone or in combination with sedatives and or tranquillizer has been recommended for anesthesia in rabbits ${ }^{[12,13]}$ The combination of Ketamine hydrochloride, xylazine and diazepam and acepromazine maleate induced effective anesthesia and produced good analgesic and muscle relaxation in this study $^{[13]}$. Creation of radial fracture was successful by electric bone saw. Radiographs indicated significant differences in the periosteal reaction in both group. On 15 days, periosteal reaction (Lipping) was observed in form of periosteal collar in all rabbits of experimental group (II) which was bridging fracture line, while in control group (I) fracture line was still visible. It indicates that transcutaneous electrical stimulation therapeutic regimen encourages early utility of the affected limbs and subsequently increases rate of callus formation and healing too. Cavadias and trueta $^{[14-17]}$ observed successful organization of the preliminary callus as well as its further development till reaching the final stage repair. More intense, well organized and uniformly dense callus bridged the gap in groupI rabbits. Radiographic evidence supported the clinically beneficial effects observed using TES in accelerating of callus formation and early remodeling of callus.

Histomorphological study of callus could better demonstrate the accelerated rate of healing observed in group II rabbits. There were uniform mixtures of fibrous and cartilaginous tissues with thin bony trabeculae with presence of extensive capillary budding as the silent feature of histomorphological changes in control rabbits. These differences revealed faster healing of fracture in treated group[is-"] phySjcai activity and radiographic evidence supported the complete ossification and remodeling which usually take place following of deposition of calcium in trabeculae. This acceleration was further substantiated an increase of alkaline phosphatase activity ${ }^{[18,19]}$ for faster conversion of cartilage into osteoid tissue as compared to control one. Otter et al. ${ }^{[20]}$ evaluated the effect of electrical stimulation on experimentally created fracture, concluded that the underlined tissue get effect by centripetal electrical field which can get controlled by electromagnetic stimulation to accelerate bone healing in more regular fashion $^{[21-24]}$. Gohat and Bose et al. ${ }^{[2]}$ evaluated the effect of electrical stimulation in fracture healing. They concluded that electrical stimulation leading to stimulate the synthesis and secretion of growth factor and factors lead to differentiations of tissue such as Bmp-4$\mathrm{Bmp} 2^{[10]}$. This finding also supports histomorphological finding of this study especially results obtained in

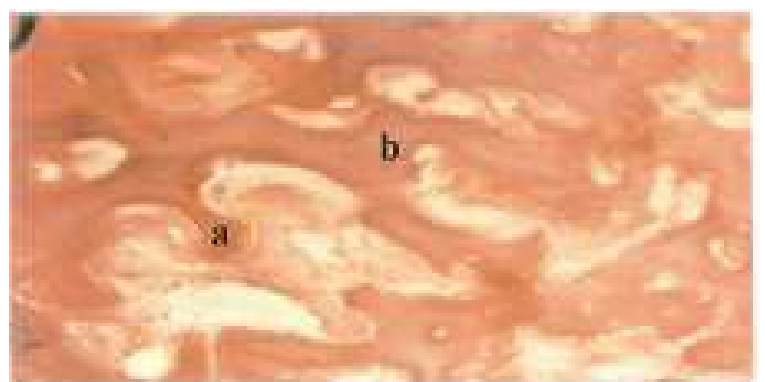

Fig. 4: Newly bone formation with tiny bony trabeculae in control group. (X100 - H\&E) . a: bony trabeculae b: osteoblast

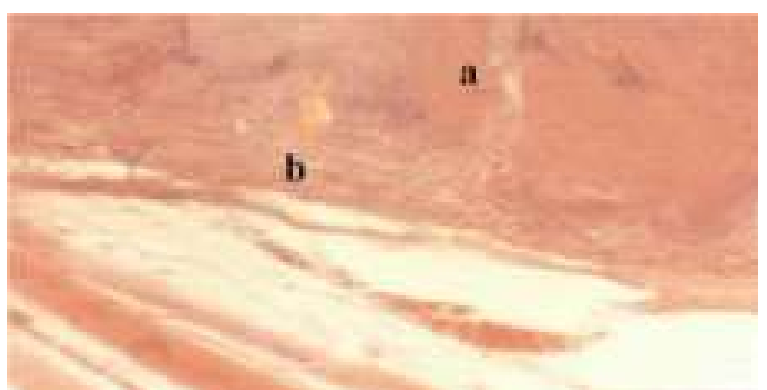

Fig. 5: Thick bony trabeculae formation (a) and maturation of Periosteal layer (b) in experimental group. (X200 - H\&E)

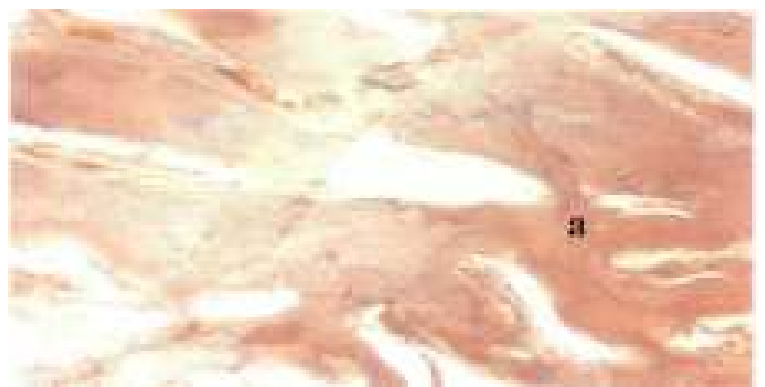

Fig. 6: a: Osteoblasts with basophilic cytoplasm in bony trabeculae formation in experimental group (X200; H\&E)

experimental rabbits. Appearance of structural pattern treated in group (I) almost similar to normal bone ${ }^{[26]}$. Haversian septum formed well with variable thickness of trabeculae in treated rabbits was observed ${ }^{[27,28]}$. Their findings showed that TES can affect on the site of fracture by stimulation of certain growth factors. Research supports the idea of a local tissue response following increasing DNA, ATP and protein (collagen) synthesis. This experimental and also researchers confirmed that the effects of TES could be multifactorial. Clinical observations, radiographic findings and histomorphological examination of callus sample supported that progress of healing, so this results showed in group II rabbits. 


\section{ACKNOWLEDGMENT}

Authors wish to express their high gratitude for approval and financial support provided by respective Faculty of Veterinary Medicine and Research Council. Tehran- Iran.

\section{REFERENCES}

1. Devise, W.J. and C.L. Runjon, 1996. Effect of volume variations on osteogenic capabilities of autogenous cancellous bone graft in dog. Am. J. Vet. Res., 57: 1501-1505.

2. Basett, C.A.L, S.N. Mitchell and S.R. Gastom, 1981. Treatment of ununited tibial diphyseal fracture with pulsing electromagnetic field. J. Bone Joint Surg., 63-A: 511-523.

3. Bolander, M.F., 1992. Regulation on fracture repair by growth factors. Procsco. Exper. Biolmed., 200: 168-170.

4. Brighton, C.T., 1981. A multicenter study of the treatment of nonunion with constant direct current. J. Bone Joint Surg. (Am), 63: 847-851.

5. Cheng, N., 1982. The effect of electric currents on ATP generation protein synthesis and membrane transport in rat skin. Clin Orthop., 171: 264-272.

6. Delitto, A., M. Strale and A. Shulman, 1992. A study of discomfort with electrical stimulation. Physical Therapy, 72: 412/224.

7. Luna, L.G., 1968. Manual of histologic/staining Methods of the Armed forces. Institute of Pathology. Mc Graw Hill Book Company, pp: 36, 76 and 168.

8. Sheila, K., 2002. Electrotherapy Evidence-Based Practice. Churchill Livingstone. 11th Edn. An Imprint of Harcourt Publishers Limited. Chap. 20, pp: 313-336.

9. Stalis, P. and P. Rokkonin, 1965. The manual repair of experimental fractures. A histoquantitative study of rat. Acta Orthop. Scan., 36: 221-229.

10. Steiss, J.E., 1981. Electrodiagnosis and electrotherapy of neuromuscular and musculoskeletal devices in domestic animals. Diss, Abst. Intn. B, 42: 1779.

11. Luo, Y. and G.B. Russell, 1998. Comparison of anesthesia induced by ketamine- fentanyl combination and maintained by proposal on etomidate in New Zealand white rabbit. Lab. Anim, Sci., 45: 264- 275.

12. Harkness, J.E. and J.E. Wagner, 1989. The Biology and Medicine of Rabbits and Rodents. Eds 3, Lea \& Febiger, Philadelphia, pp: 55-84.

13. Kazemi, D., D. Sharifi, A. Rezaie and J. Bakhtiari, 2002. Evaluation of ketamine, xylazine, acepromazine and diazepam combinations for anesthesia in rabbits. Indian J. Vet. Surg., 23: 12-15.
14. Cavadias, A.X. and J. Trueta, 1965. An experimental study of the vascular contribution to the fracture of the callus. Surg. Gynae. Obstet., 120: 731-747.

15. Carley, P.J. and S.F. Wainpel 1985. Electrotherapy for acceleration of wound healing. Low intensity direct current. Arch. Phys. Med. Rehabil., 66: 443-446.

16. Dunn, M.G., 1988. Wound healing using collagen matrix: Effect of DC electrical stimulation. J. Biomed. Material Res., 22(A2 Suppl): 191 -206.

17. Friedemberg, Z.B. and C.T. Brighton, 1966. Bioelectric potentials in bone. J. Bone. Joint. Surg. (Am), 48: 915-923.

18. Wray, J.B. and C.J. Lynch, 1959. The vascular response to fracture of the tibia in the rat. J. Bone Joint. Surg. LHA, pp: 1143-1148.

19. Singh. H., J.E. Lovell, A.G. Schiller and G.H. Kerner, 1976. Serum $\mathrm{Ca}++, \mathrm{P}+$ and Alkaline phosphase level in dogs during repair of experimental ulnar defects. Indian. Vet. J., 53: 862865.

20. Otter, M.W., K.Y. Mclead and C.T. Rubin, 1998. Experimental fracture repair. Clin. Orthop. Related Res., 355: 90-104.

21. Dickson, K. and S. Kutzmmam, 1994. Delayed unions and non-union of open tibial fracture. 302: 189-193

22. Friedenberg, Z.B. and C.T. Bringhton, 1971. Stimulation of fracture healing by direct current in the rabbit's fibula. J. Bone Joint Surg. (Am), 54: 1400-1408.

23. Hinsenkamp, M., R. Bourgois and C. Bassett, 1981. Electromagnetic stimulation of fracture repair influence on healing of fresh fractures. Acta Orthop. Beig., 44: 671-698.

24. White, N.A. and J.M . Moore, 1998. Current Techniques in Equine Surgery and Lameness. 2nd Edn., pp: 553-561.

25. Gohot, C.H., K.A.M. Bose, M.C.H. Orthop and Y.K. kang, 1988. Effects of electrical stimulation on biomedical properties of fracture healing in rabbits. Clin. Orthop., 233: 263- 273.

26. Dellmon, H.D. and J. Eurel, 1998. Textbook of Veterinary Histology. 8th Edn., pp: 47-61.

27. Dunn, W.A. and G.A. Rush, 1984. Electrical stimulation of delayed union of fracture and osteomyelitis. Southern Med. J., 77: 1530-1534.

28. Wolski, C., 2001. Stimulatory fracture management. Orthop. Technol. Rev., Vol. 3, N.J. 